\title{
MÉTODOS DE CONTROLE DE BRAQUIÁRIA (Urochloa decumbens Stapf.) EM ÁREA DE RESTAURAÇÃO ECOLÓGICA DE MATA RIPÁRIA, DF
}

\author{
CONTROL METHODS OF BRACHIARIA (Urochloa decumbens Stapf.) IN AN ECOLOGICAL RES- \\ TORATION AREA IN RIPARIAN FOREST, FEDERAL DISTRICT
}

\author{
Juliene Brito Martins Barbosa ${ }^{1}$ Willian Barros Gomes ${ }^{2}$ Juaci Vitória Malaquias ${ }^{3}$ Fabiana de Gois Aquino ${ }^{4}$ \\ Lidiamar Barbosa de Albuquerque ${ }^{4}$
}

\section{RESUMO}

Embora o capim braquiária seja uma importante forrageira para muitas regiões do Brasil, quando ocorre em áreas nativas, representa problema para o funcionamento dos ecossistemas naturais e ameaça a diversidade vegetal, ao alterar o estabelecimento de espécies nativas. O objetivo do trabalho foi avaliar três métodos de controle do capim braquiária (Urochloa decumbens Stapf.), utilizando plantas de cobertura e manta plástica, em área em processo de restauração ecológica, às margens do córrego Ponte Alta, DF. Os tratamentos foram instalados em março/2013 $\left(1^{\circ}\right)$ e dezembro/2013 $\left(2^{\circ}\right)$, como seguem: T1 - plantio de mudas de amendoim-forrageiro (Arachis pintoi Krapov. \& W.C. Greg.); T2 - manta plástica; T3 - semeadura a lanço do cultivar estilosantes Campo Grande (Stylosanthes capitata Vogel + Stylosanthes macrocephala M.B. Ferreira \& Sousa Costa) e T4 - testemunha, com delineamento em três blocos completos casualizados, em fatorial (4 tratamentos $\mathrm{x} 2$ períodos). Foi realizado o monitoramento mensal da percentagem de cobertura das plantas. A percentagem de cobertura foi comparada entre os dois períodos e entre os tratamentos por meio da ANOVA e do teste Tukey. No primeiro período, não houve diferenças significativas na cobertura de braquiária entre os tratamentos, exceto para a testemunha que foi maior $(88,85 \%)$. No segundo período, os tratamentos se diferenciaram entre si, com menor cobertura de braquiária com a manta plástica $(11,65 \%)$, seguida do tratamento com estilosantes (19\%). Os tratamentos com uso de manta plástica e semeadura de estilosantes (em alta densidade) foram mais eficientes para o controle da braquiária. Espécies nativas com potencial para o controle de espécies exóticas agressívas podem auxiliar o processo de restauração ecológica.

Palavras-chave: plantas invasoras e exóticas; Arachis; Stylosanthes; manta plástica.

\section{ABSTRACT}

Although Brachiaria is an important forage grass for many regions of Brazil, when it occurs in native areas, represents a problem for the functioning of natural ecosystems and threats to plant diversity. The objective was to evaluate three methods of control of Brachiaria, using cover plants and plastic coverage. The study was carried out in banks of Ponte Alta River, Gama, DF, Brazil, an area in process of restoration. The experimental design was three complete randomized blocks in a factorial (4 types of treatments $\mathrm{x} 2$ times), with three replications. The treatments were installed in March/2013 (1st) and December/2013 (2nd), as follows: T1 - planting peanut-forage seedlings (Arachis pintoi Krapov W.C. \& Greg.); T2 - plastic coverage (1.20 m x 2 m); T3 - seeding of Stylosanthes Campo Grande (Stylosanthes capitata Vogel + Stylosanthes macrocephala M. B. Ferreira \& Sousa Costa) and T4 - control. The monthly monitoring of the percent-

1 Agrônoma, Bolsista DTI do CNPq, Embrapa Cerrados, Rod. Brasília/Fortaleza, BR 020, Km 18, Caixa Postal 08223, CEP 73310-970, Brasília (DF), Brasil. julieneagro@gmail.com

2 Gestor Ambiental, Mestrando do Programa de Pós-Graduação em Ciências Ambientais, Universidade de Brasília, Campus Planaltina, Área Universitária 1, Vila Nossa Senhora de Fátima, Planaltina, CEP 73345-010, Brasília (DF), Brasil.wbwilliangomes@gmail.com

3 Estatístico, MSc., Analista, Embrapa Cerrados, Rod. BR-020, Km 18 Caixa Postal 08223, CEP 73310-970, Planaltina (DF), Brasil. juaci.malaquias@embrapa.br

4 Bióloga, Dr ${ }^{\mathrm{a}}$., Pesquisadora da Embrapa Cerrados, Rod. BR-020, Km 18 Caixa Postal 08223, CEP 73310-970, Planaltina (DF), Brasil. fabiana.aquino@embrapa.br / lidiamar98@yahoo.com

Recebido para publicação em 25/02/2016 e aceito em 11/10/2017

Ci. F1., v. 28, n. 4, out. - dez., 2018 
age of coverage of the plants was conducted. The percentage of coverage was compared between the two periods and between the treatments by ANOVA and Tukey test. In the first period, there were no significant differences in grass cover among treatments, except for control, which was higher $(88.85 \%)$. In the second period, the treatments differed among themselves, with less grass cover in plastic coverage (11.65\%) and Stylosanthes (19\%). The plastic coverage and Stylosanthes (high density) were the most efficient treatments for the control of grass, regardless of period. Native species with potential for the control of aggressive alien species can assist the ecological restoration.

Keywords: invasive and exotic plants; Arachis; Stylosanthes; plastic cover.

\section{INTRODUÇÃO}

O processo de restauração ecológica é afetado pelo equilíbrio competitivo entre plantas nativas e exóticas invasoras. O capim braquiária (Urochloa spp.) tem papel de destaque nessa dinâmica, podendo se tornar invasora, em determinadas áreas, e impor barreiras ao processo de regeneração natural (PIVELLO, 2011). Sua capacidade de se tornar invasora está associada à capacidade de adaptação em quase todo tipo de solo e clima, com baixa exigência em termos de fertilidade do solo e com intensa produção de sementes (PEREIRA; CAMPOS, 2001). Embora o capim braquiária seja uma importante forrageira para muitas regiões do Brasil, quando ocorre em áreas nativas, representa problema para o funcionamento dos ecossistemas naturais e ameaça a diversidade vegetal, ao alterar o estabelecimento de espécies nativas (MARTINS; LEITE; HARIDASAN, 2004, PIVELLO, 2011) e a sucessão ecológica (SAMPAIO; HOLL; SCARIOT, 2007). As gramíneas exóticas têm sido apontadas como um dos fatores responsáveis pelo aumento de mortalidade e inibição do crescimento das mudas plantadas em áreas de restauração ecológica (SILVEIRA et al., 2013).

Métodos de controle de gramíneas exóticas vêm sendo testados em áreas de restauração ecológica, com o intuito de acelerar o processo sucessional (MARTINS; LEITE; HARIDASAN, 2004; FIGUEIREDO et al., 2009; RODRIGUES, 2010; MARTINS, 2011; PIVELLO, 2011; SILVEIRA et al., 2013; FLORIDO, 2015). Na restauração, buscam-se práticas que apresentem baixo impacto ambiental para o controle de espécies exóticas e que promovam o desenvolvimento das mudas de espécies nativas, de modo que o próprio sombreamento ocasionado pelas plantas nativas auxilie no controle das gramíneas exóticas (MARTINS, 2011). No entanto, há lacunas na validação e na divulgação de resultados sobre a eficiência de diferentes estratégias para controle de gramíneas exóticas, sobretudo, quanto aos custos financeiros envolvidos. Os distintos métodos incluem: mecânico (capina), químico, cultural (fogo e pastoreio), entre outras.

Segundo Silveira et al. (2013), o controle químico prejudica a densidade das espécies nativas que poderiam ter se regenerado por sementes ou rebrota nas entrelinhas, mas favorece o desenvolvimento das mudas e o aumento de sua cobertura. $\mathrm{O}$ uso de herbicidas tem sido questionado, principalmente devido ao risco em alcançar os mananciais hídricos dentre outros impactos à fauna e à flora (TUFFI SANTOS et al., 2005; NAVE et al., 2009).

Alguns estudos têm testado o uso de espécies de cobertura, sobretudo leguminosas, no controle de plantas exóticas (RODRIGUES, 2010; MARTINS, 2011). As vantagens das espécies de leguminosas usadas como plantas de cobertura incluem: rápido crescimento, capacidade de fixar o nitrogênio atmosférico, grande produção de biomassa vegetal e sistema radicular profundo (ALCÂNTARA, 2000; RODRIGUES et al., 2004). Estas características tendem a melhorar a condição física do solo pelo aumento de macroporos devido à penetração de raízes, aumento da fauna edáfica pela maior disponibilidade de "alimentos" e pela atração de polinizadores (MIYASAKA et al., 1984). Dentre os gêneros de leguminosas forrageiras tropicais destacam-se: o Stylosanthes e o Arachis, nativos da flora brasileira, com ampla adaptação e resistência às pressões bióticas e abióticas (BARCELLOS et al., 2001).

Outra técnica utilizada no controle de plantas exóticas é a cobertura plástica do solo, que evita a lixiviação, conserva a estrutura do solo, reduz a adubação, retém a umidade, propicia menor amplitude térmica, aumenta a atividade microbiana, aumenta a fotossíntese e o rendimento das culturas, entre outros benefícios (SAMPAIO; ARAUJO, 2001). Em síntese, existem diversos métodos de manejo de plantas exóticas e a lógica tem sido obter um balanço entre o controle das populações de espécies indesejadas e a 
manutenção da capacidade de regeneração natural das espécies nativas (SILVEIRA et al., 2013).

Nesse sentido, o objetivo do trabalho foi avaliar três métodos de controle do capim braquiária (Urochloa decumbens Stapf.), utilizando plantas de cobertura (Stylosanthes e Arachis) e manta plástica, em área em processo de restauração ecológica, às margens do córrego Ponte Alta, DF. Com este estudo espera-se contribuir para a recomendação de práticas voltadas à restauração ecológica de zonas ripárias.

\section{METODOLOGIA}

\section{Área de estudo}

O estudo foi realizado em uma área experimental localizada às margens do córrego Ponte Alta, Núcleo Rural Ponte Alta, cidade satélite do Gama, Distrito Federal (1556'57,27'S e 04807'28,24" W). Há cerca de 30 anos, a vegetação original foi substituída por pastagens de capim braquiária (Urochloa decumbens Stapf.). Posteriormente, houve manejo da área alternando, bianualmente, o plantio de milho com a pastagem de braquiária. O solo predominante é Latossolo Vermelho Distrófico, mas ocorre também Latossolo Vermelho-Amarelo Distrófico, ambos de textura argilosa (REATTO, 2013). A altitude média local é de $960 \mathrm{~m}$. O clima é do tipo Aw, segundo Köppen, com verão úmido e chuvoso (outubro a abril) e inverno seco e relativamente frio (maio a setembro) (Figura 1), seguindo as características do bioma Cerrado, com temperatura média anual de $21^{\circ} \mathrm{C}$ e a pluviosidade média anual é cerca de $1600 \mathrm{~mm}$ (INSTITUTO NACIONAL DE METEOROLOGIA, 2014).

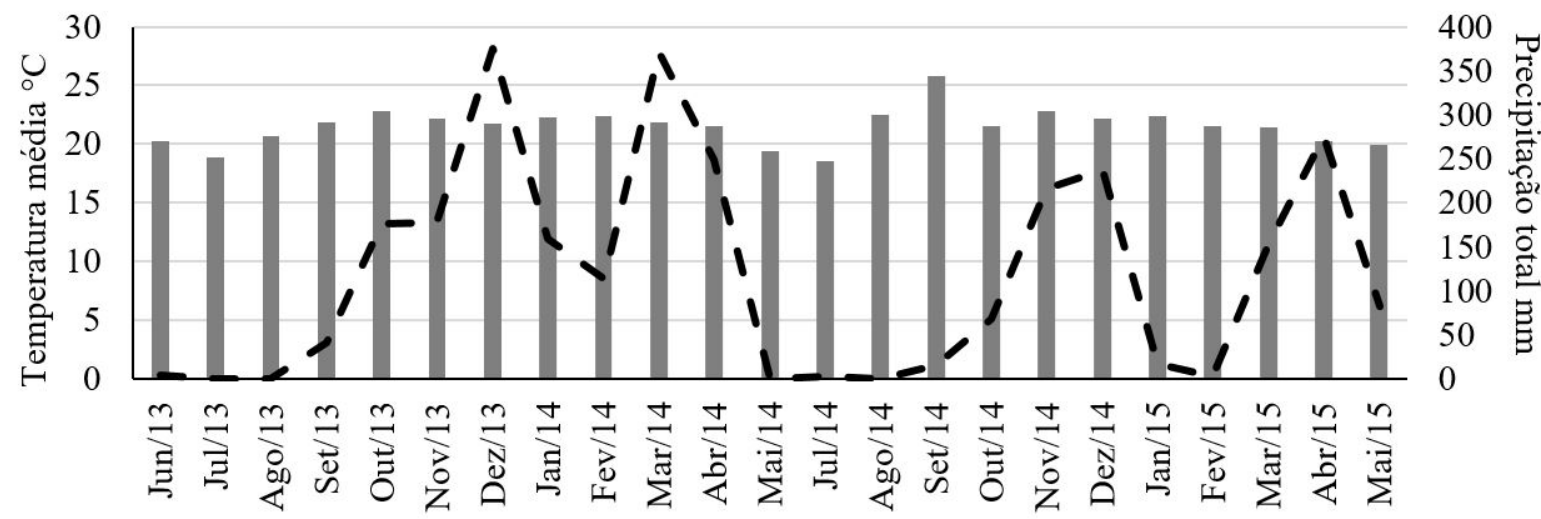

FIGURA 1: Temperatura média e precipitação mensal registradas na área experimental, Núcleo Rural Ponte Alta, cidade satélite do Gama-DF ( $15^{\circ} 56^{\prime} 57,27^{\prime}$ 'S e $\left.048^{\circ} 07^{\prime} 28,24^{\prime \prime} \mathrm{W}\right)$.

FIGURE 1: Average temperature and precipitation recorded in the experimental area, Ponte Alta River, Gama, DF (15 56' $57,27^{\prime \prime}$ S e $048^{\circ} 07^{\prime} 28,24^{\prime \prime}$ W).

\section{Delineamento experimental}

Este trabalho foi desenvolvido dentro do projeto AquaRipária (implantado em dez/2011, área de mata ripária com 2,56 ha), em uma de suas técnicas de plantio para a restauração ecológica - Nucleação de Anderson 3 x 3 (plantio em "+" com espécie arbórea no centro do núcleo e quatro espécies arbustivas nas pontas e distantes 1,0 m entre si, e 3,0 m de distância entre os núcleos).

Os três métodos de controle do capim braquiária foram implantados logo após o coroamento das mudas, como segue: T1 - plantio de mudas de amendoim-forrageiro (Arachis pintoi Krapov. \& W.C. Greg. cv. Amarillo); T2 - manta plástica preta (2,0 m x 2,0 m); T3 - semeadura a lanço e em alta densidade do cultivar estilosantes Campo Grande (Stylosanthes capitata Vogel + Stylosanthes macrocephala M.B. Ferreira $\&$ Sousa Costa) e T4 - testemunha (sem cobertura) (Figura 2 e Tabela 1). 

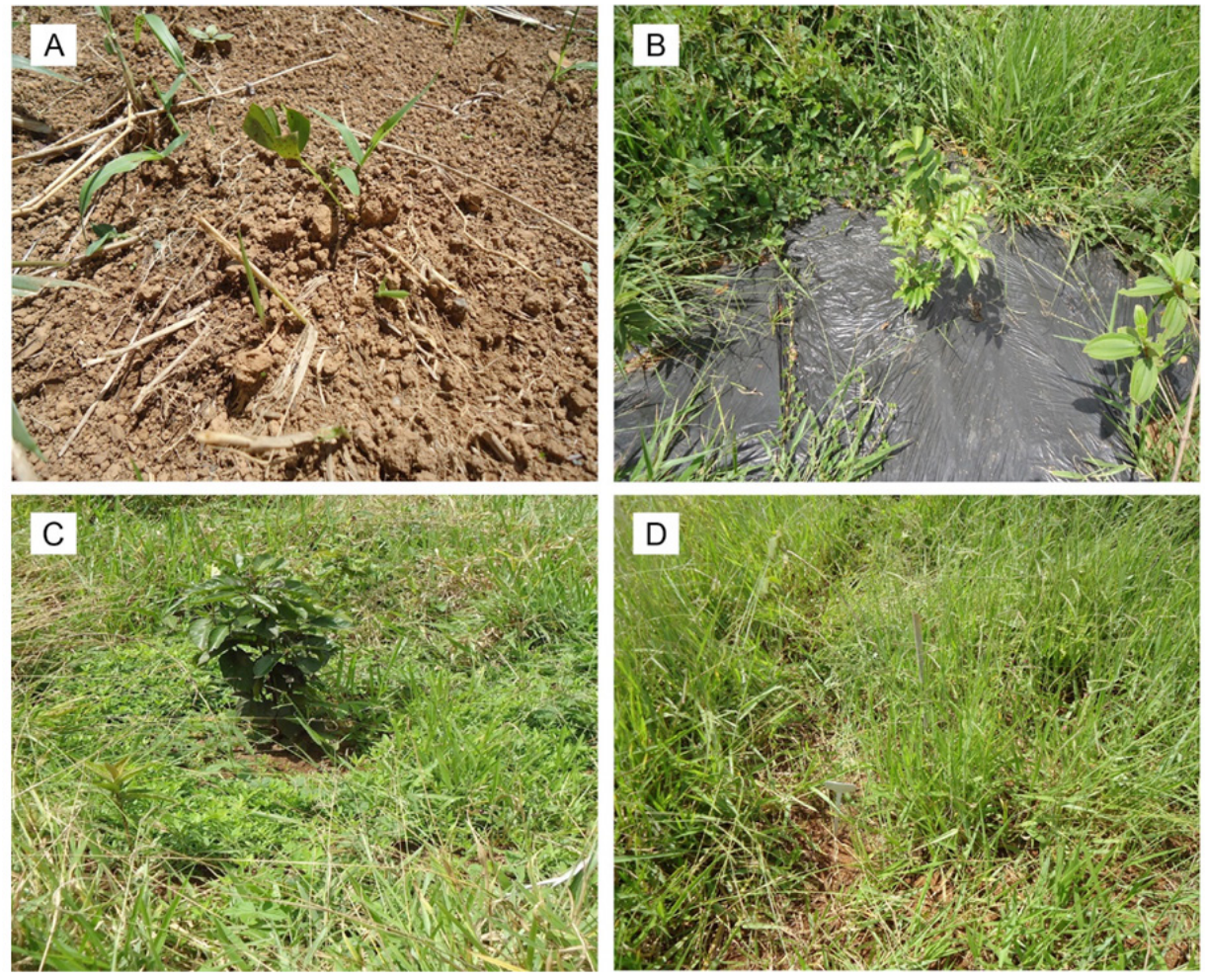

FIGURA 2: A) Plantio de mudas de Arachis; B) Manta plástica; C) Semeadura a lanço do cultivar estilosantes Campo Grande e D) testemunha.

FIGURE 2: A) Arachis planting seedlings; B) Plastic cover; C) Seeding of Stylosanthes Campo Grande and D) control.

TABELA 1: Descrição dos tratamentos para controle de braquiária (Urochloa decumbens Stapf.) em experimento de restauração ecológica, DF.

TABLE 1: Treatments tested for control of Brachiaria (Urochloa decumbens Stapf.) in an experiment of ecological restoration, DF.

\begin{tabular}{|c|c|c|}
\hline \multirow[t]{2}{*}{ Tratamentos $(\mathrm{T})$} & \multicolumn{2}{|l|}{ Quantidade por núcleo } \\
\hline & Mar-13 & Dec-13 \\
\hline $\begin{array}{l}\mathrm{T} 1 \text { - plantio de mudas de amendoim- } \\
\text { forrageiro }\end{array}$ & $\begin{array}{l}40 \text { mudas ( } 8 \text { mudas/planta), } \\
\text { distribuídas em círculo }\end{array}$ & $\begin{array}{c}60 \text { mudas (12 mudas/planta), } \\
\text { distribuídas em raio }\end{array}$ \\
\hline T2 - manta plástica & $2,0 \mathrm{~m} \times 2,0 \mathrm{~m}$ & $2,0 \mathrm{~m} \times 2,0 \mathrm{~m}$ \\
\hline $\begin{array}{l}\text { T3 - semeadura a lanço e em alta } \\
\text { densidade de estilosantes }\end{array}$ & $\begin{array}{c}200 \mathrm{~g} \text { de sementes distribuídas } \\
\text { em círculo }(40 \mathrm{~g} / \mathrm{muda}) \mathrm{em} \\
\text { duas etapas: } 100 \mathrm{~g} / \text { núcleo } \\
\text { (março/2013), mais } 100 \mathrm{~g} \text { em } \\
\text { abril/2013. }\end{array}$ & $\begin{array}{l}200 \mathrm{~g} \text { de sementes distribuídas } \\
\text { em raio ( } 40 \mathrm{~g} / \text { muda })\end{array}$ \\
\hline T4 - testemunha & sem cobertura & sem cobertura \\
\hline
\end{tabular}


Os tratamentos foram instalados em março/2013 e dezembro/2013. Os experimentos foram monitorados, mensalmente, em dois períodos diferentes: abril a agosto de 2013 (período 1) e janeiro de 2014 a maio de 2014 (período 2). O delineamento experimental foi em blocos completos casualizados (DBC), em fatorial (4 tipos de tratamentos $\mathrm{x} 2$ períodos), com três repetições. A análise possui como fatores: Tratamento (T1 a T4) e período (2013 e 2014).

Foi realizado o monitoramento mensal da percentagem de cobertura do capim braquiária, regenerantes (plântulas e jovens de espécies nativas), lianas, invasoras (outras espécies não graminoides) e solo exposto. A percentagem de cobertura foi determinada utilizando um gabarito de $50 \mathrm{~cm} \times 50 \mathrm{~cm}$, lançado aleatoriamente na área amostral. Os dados foram comparados por meio da Análise de Variância (ANOVA) e do teste de Tukey, em nível de significância de 5\%, entre os períodos de avaliação e os tratamentos adotados. As análises foram realizadas no software SAS versão 9.1.2.

\section{Leguminosas testadas}

No Brasil, ocorrem 25 espécies do gênero Stylosanthes Sw. (LEWIS; MACKINDER; LOCK, 2005), representadas por ervas anuais ou perenes, subarbustos eretos ou prostrados, com altura de $12-150 \mathrm{~cm}$ (COSTA; SARTORI; POTT, 2008). Dentre as leguminosas, é o gênero com maior número de cultivares tropicais usadas no mundo como pastagens (KARIA et al., 2002). As principais espécies de Stylosanthes com potencial de uso no Brasil são $S$. guianensis, S. capitata e $S$. macrocephala (KARIA; ANDRADE, 1996). O Stylosanthes capitata e o $S$. macrocephala são componentes do cultivar estilosantes Campo Grande, que foi lançado pela Embrapa Gado de Corte e é reconhecido por sua fixação biológica de nitrogênio, por ser boa fonte de proteína, grande potencial forrageiro e por ser boa alternativa para a melhoria da estruturação do solo, reduzindo as perdas por erosão, contribuindo para a descompactação do solo, principalmente em solos arenosos e argilo-arenosos, pois a cultivar é adaptada a solos pobres (EMBRAPA, 2007).

No Brasil, ocorrem 69 espécies do gênero Arachis (62 espécies exclusivas), sendo representadas por ervas anuais ou perenes e que alcançam de 20 a $50 \mathrm{~cm}$ de altura (KRAPOVICKAS; GREGORY, 1994). As espécies desse gênero têm: 1) hábito rasteiro e estolonífero e, geralmente, lançam densas quantidades de estolões ramificados, com pontos de crescimento bem protegidos do pastejo, que enraízam até $1,50 \mathrm{~m}$ horizontalmente em todas as direções; 2) raiz pivotante (aproximadamente 1,60 m de profundidade), com capacidade de extrair água das camadas mais profundas, principalmente, em condições menos favoráveis (LIMA et al., 2003); e 3) fruto que se desenvolve abaixo da superfície do solo (VALLS; MAASS; LOPES, 1994), característica que contribui para a regeneração e persistência da planta (MONTENEGRO; PINZÓN, 1997). Essas espécies se adaptam bem em solos de baixa a média fertilidade e toleram aqueles com alta saturação de alumínio (ácidos), mas respondem bem à calagem e adubação fosfatada (RINCÓN et al., 1992).

\section{Avaliação dos custos}

O custo de cada método testado foi determinado com base nos custos fixos e variáveis inerentes aos gastos referentes à implantação e à manutenção dos experimentos em campo. Estes custos foram comparados a uma estimativa das despesas simulando a aplicação de herbicida. Para realizar a estimativa do custo de cada tratamento, foi adaptado o método descrito por Mantoani, Dias e Torezan (2016), que avaliaram a aplicação de herbicida no controle de gramíneas exóticas em área revegetada. Por meio de uma equação foi calculado o custo de cada método por hectare (ha), referente ao período de implantação do experimento (2013 a 2014).

\section{RESULTADOS E DISCUSSÃO}

Para o primeiro período avaliado (abril a agosto de 2013), não houve diferenças significativas na cobertura do capim braquiária entre os tratamentos. Somente a testemunha apresentou cobertura significativamente maior (88,85\%). No segundo período (janeiro a maio de 2014), os tratamentos se diferenciaram entre si, com maior cobertura de braquiária na testemunha, seguida do tratamento Arachis (48,05\%), estilo- 
santes (19\%) e manta plástica (11,65\%) (Tabela 2).

TABELA 2: Percentagem média da cobertura para cada parâmetro avaliado nos tratamentos [T1 - mudas de amendoim-forrageiro (Arachis pintoi Krapov. \& W.C. Greg.); T2 - manta plástica; T3 - semeadura a lanço do cultivar estilosantes Campo Grande (Stylosanthes capitata Vogel + Stylosanthes macrocephala M.B. Ferreira \& Sousa Costa) e T4 - testemunha] para o controle de braquiária (Urochloa decumbens Stapf.), entre abril a agosto 2013 e janeiro a maio 2014, em experimento de restauração ecológica de mata ripária, córrego Ponte Alta, DF.

TABLE 2: Average percentage of coverage for each parameter evaluated in treatments [T1 - forage peanut (Arachis pintoi Krapov. \& W.C. Greg.); T2 - plastic coverage; T3 - seeding of Stylosanthes Campo Grande (Stylosanthes capitata Vogel + Stylosanthes macrocephala M.B. Ferreira \& Sousa Costa) and T4 - control] for the control of Urochloa decumbens, between April and August 2013 and January and May 2014, in ecological restoration experiment of riparian forest, Ponte Alta River, DF.

\begin{tabular}{|c|c|c|c|c|c|c|c|c|}
\hline \multirow[b]{2}{*}{ Braquiária } & \multicolumn{2}{|l|}{$\begin{array}{l}\text { Amendoim- } \\
\text { forrageiro }\end{array}$} & \multicolumn{2}{|l|}{$\begin{array}{l}\text { Manta } \\
\text { plástica }\end{array}$} & \multicolumn{2}{|c|}{ Estilosantes } & \multicolumn{2}{|l|}{ Testemunha } \\
\hline & Média & $\mathrm{F}$ & Média & $\mathrm{F}$ & Média & $\mathrm{F}$ & Média & $\mathrm{F}$ \\
\hline 2013 & $26,67 \mathrm{Aa}$ & 30,9 & $29,42 \mathrm{Aa}$ & 35,23 & $20,57 \mathrm{Aa}$ & 0,38 & $88,85 \mathrm{Ab}$ & 90,51 \\
\hline 2014 & $48,05 \mathrm{Ba}$ & 7,26 & $11,65 \mathrm{Bb}$ & 2,62 & $19 \mathrm{Ac}$ & 6,99 & $52,6 \mathrm{Bd}$ & 0,29 \\
\hline \multicolumn{9}{|l|}{ Regenerantes } \\
\hline 2013 & $0,92 \mathrm{Aa}$ & 2,49 & $0,72 \mathrm{Aa}$ & 2,09 & $0,39 \mathrm{Aa}$ & 1,00 & $0,29 \mathrm{Aa}$ & 3,18 \\
\hline 2014 & $0,02 \mathrm{Aa}$ & 1,86 & $0 \mathrm{Aa}$ & 0,55 & $0 \mathrm{Aa}$ & 1,00 & $1,62 \mathrm{Aa}$ & 3,88 \\
\hline \multicolumn{9}{|l|}{ Lianas } \\
\hline 2013 & $5,26 \mathrm{Aa}$ & 3,61 & $0,62 \mathrm{Aa}$ & 1,97 & $3,27 \mathrm{Aa}$ & 12,06 & $2,21 \mathrm{Aa}$ & 10,39 \\
\hline 2014 & 4,9 Aa & 5,23 & $1,82 \mathrm{Aa}$ & 0,98 & $2 \mathrm{Aa}$ & 5,19 & 7,58 Bb & 35,75 \\
\hline \multicolumn{9}{|l|}{$\begin{array}{l}\text { Espécies } \\
\text { Invasoras }\end{array}$} \\
\hline 2013 & $64,27 \mathrm{Aa}$ & 0,16 & $2,95 \mathrm{Ab}$ & 5,05 & $67,97 \mathrm{Aa}$ & 7,74 & $8,79 \mathrm{Ab}$ & 26,28 \\
\hline 2014 & $45,34 \mathrm{Aa}$ & 2,54 & $2,85 \mathrm{Ab}$ & 2,41 & $36,1 \mathrm{Ba}$ & 3,87 & $37,31 \mathrm{Ba}$ & 0,70 \\
\hline \multicolumn{9}{|l|}{ Solo exposto } \\
\hline 2013 & $1,78 \mathrm{Aa}$ & 19,45 & $1,1 \mathrm{Aa}$ & 0,56 & $2,76 \mathrm{Aa}$ & 56,47 & $1,51 \mathrm{Aa}$ & 60,84 \\
\hline 2014 & $4,1 \mathrm{Aa}$ & 4,30 & $2,02 \mathrm{Aa}$ & 0,01 & $6,67 \mathrm{Aa}$ & 0,68 & $8,44 \mathrm{Aa}$ & 0,04 \\
\hline
\end{tabular}

As letras minúsculas representam a comparação entre os tratamentos. As letras maiúsculas representam a comparação entre os períodos avaliados. Letras diferentes indicam diferenças significativas a 5\% de significância.

Ao se avaliar a cobertura de regenerantes, verificou-se que não houve diferença significativa em nenhum tratamento e nem entre os períodos avaliados. A pouca abundância de regenerantes, provavelmente, seja em função do histórico de uso da área, em que houve uso intenso, com rotação de cultura, ora com pastagem de braquiária ora com cultivo de milho. Esse manejo pode ter influenciado negativamente o estoque do banco de sementes e a rebrota das espécies nativas.

As lianas não apresentaram diferenças expressivas em sua cobertura, exceto para a testemunha, em 2014. A cobertura das espécies invasoras (não graminoides) foi significativamente menor no tratamento manta plástica para ambos os períodos avaliados (Tabela 2).

Não houve diferença significativa entre a percentagem de solo exposto entre os tratamentos. No entanto, houve uma tendência de maior percentagem de solo exposto no período de dezembro de 2013 a março de 2014.

A comparação entre os períodos avaliados mostrou que a cobertura do capim braquiária foi maior em 2014 no tratamento amendoim-forrageiro. Entretanto, a cobertura de outras espécies invasoras diminuiu 
nesse período. Verificou-se que o amendoim-forrageiro diminuiu significativamente seu potencial de controle do capim braquiária, mesmo na estação chuvosa. Ao contrario do relatado por Barcellos et al. (2008), que colocam que esta espécie diminui a sua biomassa na seca, o que pode afetar seu potencial de competição com as gramíneas exóticas.

Ao se analisar a cobertura de gramíneas exóticas, verificou-se que a semeadura em alta densidade de estilosantes apresentou o mesmo potencial de controle da braquiária, nos dois períodos avaliados (Tabela 2). Portanto, o período seco não prejudicou o desempenho do cultivar de estilosantes utilizado. Os estilosantes são tolerantes à seca e têm grande capacidade de colonização por serem adaptados a solos pobres (ANDRADE; KARIA, 2000; ANDRADE; ASSIS; SALES, 2010).

A área-testemunha apresentou menor cobertura de braquiária em 2014, por outro lado, houve aumento significativo de lianas e outras espécies invasoras (Tabela 2), que foram capazes de colonizar os eventuais espaços deixados pelas gramíneas exóticas.

A manta plástica e o estilosantes (em alta densidade) foram mais eficientes para conter a braquiária, independentemente do período de implantação. Embora a manta plástica tenha sido eficiente, sua aplicação em campo foi mais laboriosa (requerendo duas substituições/ano) e não deve ser recomendada para áreas que apresentem alta cobertura de regenerantes de espécies nativas ou para grandes áreas, pois o processo de restauração se tornará oneroso. $\mathrm{O}$ acompanhamento em um prazo maior que o adotado no presente estudo é recomendado para avaliar a eficiência da manta plástica ao longo do tempo. O custo total (implantação + manutenção) por hectare/ano da manta foi de $\mathrm{R} \$ 2.368,00$ e do estilosantes foi menor ( $\mathrm{R} \$ 1.840,00)$ (Tabela $3)$.

O cultivar estilosantes Campo Grande apresenta características importantes, tais como: capacidade de colonização, por sua adaptação a solos de baixa fertilidade e em ampla faixa de pH (4.0-8.3), formação de potentes sistemas radiculares, tolerância à estiagem e associação com bactérias fixadoras de N (ANDRADE; KARIA, 2000; ANDRADE; ASSIS; SALES, 2010). Essas características podem contribuir para a diminuição dos gastos com adubação de cobertura e também com o custo de manutenção que requer no máximo uma roçagem/ano (R\$ 160,00) (Tabela 3).

TABELA 3: Custo total $(\mathrm{Ct})$ [implantação $(\mathrm{Ci})+$ manutenção $(\mathrm{Cm})$ ] calculado por hectare nos tratamentos testados para controle de braquiária (Urochloa decumbens Stapf.) $[\mathrm{T} 1$ = mudas de amendoim-forrageiro (Arachis pintoi Krapov. \& W.C. Greg); T2 = manta plástica; T3 = semeadura a lanço do cultivar estilosantes Campo Grande (Stylosanthes capitata Vogel + Stylosanthes macrocephala M.B. Ferreira \& N.M. Sousa Costa) e T4 = testemunha] comparado com a aplicação de Herbicida Glifosato ${ }^{\circledR}$, descrita por Mantoani, Dias e Torezan (2016). A base de cálculo foi para um hectare de área plantada com espécies nativas (técnica de nucleação $3 \times 3 \mathrm{~m}$ ), somando-se 400 núcleos (2000 mudas/ha.), 01 núcleo $=4 \mathrm{~m}^{2}$.

TABLE 3: Estimated cost per hectare of treatments for the control of Brachiaria $[\mathrm{T} 1=$ forage peanut (Arachis pintoi Krapov. \& W.C. Greg.); T2 = plastic coverage; T3 = seeding of Stylosanthes (Stylosanthes capitata Vogel + Stylosanthes macrocephala M.B. Ferreira \& Sousa Costa) and T4 = control] compared to the application of Glyphosate ${ }^{\circledR}$ Herbicide, described by Mantoani, Dias e Torezan (2016). The base of calculation was for one hectare of area planted with native species (nucleation $3 \times 3 \mathrm{~m}$ ), adding up to 400 nuclei (2000 seedlings/ha.), 01 nuclei $=4$ sqm.

\begin{tabular}{c|c|c|c|c}
\hline \multirow{2}{*}{$\begin{array}{c}\text { Composição do } \\
\text { Custo }\end{array}$} & $\begin{array}{c}\text { T1: Amendoim- } \\
\text { forrageiro }\end{array}$ & $\begin{array}{c}\text { T2: Manta } \\
\text { plástica preta }\end{array}$ & $\begin{array}{c}\text { T3: Semeadura de } \\
\text { estilosantes }\end{array}$ & $\begin{array}{c}\text { Simulação do uso de } \\
\text { Herbicida }\end{array}$ \\
\hline $\begin{array}{c}\text { DT (diária do } \\
\text { trabalhador) } \times \text { ND } \\
\text { (n. dias trabalhados: } \\
\text { roçagem, } \\
\text { pulverização, } \\
\begin{array}{c}\text { substituição manta, } \\
\text { coroamento, } \\
\text { replantio). }\end{array}\end{array}$ & $\mathrm{R} \$ 80,00 \times 6$ & $\mathrm{R} \$ 80,00 \times 5$ & $\mathrm{R} \$ 80,00 \times 4$ & $\mathrm{R} \$ 80,00 \times 4$ \\
\hline
\end{tabular}


TABELA 3: Continuação...

TABLE 3: Continued..

\begin{tabular}{|c|c|c|c|c|}
\hline \multirow[b]{2}{*}{$\begin{array}{l}\text { Composição do } \\
\text { Custo }\end{array}$} & \multicolumn{4}{|c|}{ Tratamentos } \\
\hline & $\begin{array}{l}\text { T1: Amendoim- } \\
\text { forrageiro }\end{array}$ & $\begin{array}{l}\text { T2: Manta } \\
\text { plástica preta }\end{array}$ & $\begin{array}{l}\text { T3: Semeadura de } \\
\text { estilosantes }\end{array}$ & $\begin{array}{c}\text { Simulação do uso de } \\
\text { Herbicida }\end{array}$ \\
\hline \multirow[t]{2}{*}{$\begin{array}{l}\text { Qi (quantidade de } \\
\text { insumos/ha.) x Vi } \\
\text { [valor dos insumos } \\
\text { (R\$) utilizados } \\
\text { por técnica (muda; } \\
\text { manta; sementes ou } \\
\text { herbicida). }\end{array}$} & $\begin{array}{c}\text { Mudas/núcleo = } 60 \\
\text { x 0,29; Mudas/ha. } \\
=24.000 \times 0,29= \\
6960,00 .\end{array}$ & \begin{tabular}{|c|} 
Arame liso \\
$(2,8 \mathrm{~mm}) /$ \\
núcleo $=2 \mathrm{~m} \times$ \\
0,$24 ;$ Arame/ha. \\
$=800 \mathrm{~m} \times 0,24 ;$ \\
Manta/núcleo \\
$=4 \mathrm{~m}^{2} \times 0,19 ;$ \\
Manta/ ha. $=$ \\
$1600 \mathrm{~m}^{2} \times 0,19$.
\end{tabular} & $\begin{array}{l}\text { Sementes/núcleo = } \\
\text { 200g; Sementes/ha. } \\
=80 \mathrm{Kg} \times 17,00 .\end{array}$ & $\begin{array}{c}\text { Glifosato }{ }^{\circledR} / \text { aplicação } \\
=4 \mathrm{~L} / \mathrm{ha} . \times 19,00 . \\
\text { Aluguel } 01 \text { roçadeira } \\
\text { costal = } 1 \text { dia } \times 65,00 ; \\
\text { Lubrificantes e } \\
\text { combustível }=5 \mathrm{~L} / \mathrm{ha} \text {. } \\
\text { x 3,00; Aluguel de } 01 \\
\text { Pulverizador }=1 \text { dia } \times \\
20,00 .\end{array}$ \\
\hline & $\begin{array}{c}\text { Manutenção: } \\
\text { Replantio 50\% mudas } \\
\text { (Amendoim) }=12.000 / \\
\text { ha. x } 0,29 .\end{array}$ & \begin{tabular}{|} 
Manutenção: \\
Substituições \\
manta $=02$ \\
x 656,00 \\
$(192+304+160$ \\
$=656,00)$.
\end{tabular} & $\begin{array}{c}\text { Manutenção: } \\
\text { Aluguel 01 } \\
\text { roçadeira costal } \\
=1 \text { dia x } 65,00 ; \\
\text { Lubrificantes e } \\
\text { combustível }=5 \mathrm{~L} / \\
\text { ha. } \times 3,00 .\end{array}$ & $\begin{array}{c}\text { Manutenção: } \\
\text { Glifosato = 4 } \\
\text { Aplicações x 176,00; } \\
\text { Aluguel de 01 } \\
\text { Pulverizador/dia = } \\
20,00 .\end{array}$ \\
\hline $\begin{array}{c}\mathrm{Ci} / \mathrm{ha} .=[\mathrm{DT} \times \mathrm{ND}+ \\
\left.\sum(\mathrm{Qi} \times \mathrm{Vi})\right]\end{array}$ & $\mathrm{R} \$ 7.940,00$ & $\mathrm{R} \$ 1.056,00$ & $\mathrm{R} \$ 1.680,00$ & $\mathrm{R} \$ 496,00$ \\
\hline $\mathrm{Cm} /$ anual & $\mathrm{R} \$ 3.480,00$ & $\mathrm{R} \$ 1.312,00$ & $\mathrm{R} \$ 160,00$ & $\mathrm{R} \$ 704,00$ \\
\hline Custo Total (Ct) & $\mathrm{R} \$ 11.420,00$ & $\mathrm{R} \$ 2.368,00$ & $\mathrm{R} \$ 1.840,00$ & $\mathrm{R} \$ 1.200,00$ \\
\hline
\end{tabular}

Stylosanthes spp. tem sido testado como um substituto das gramíneas nativas em projetos de revegetação nos quais algumas espécies são utilizadas para substituir eficazmente as plantas invasoras (PHENGSAVANH; LEDIN, 2003).

Quanto ao Arachis (Fabaceae, Papilionoideae), há espécies desse gênero indicadas para cobertura de solos em culturas perenes com o objetivo de controlar erosões, competir com as ervas daninhas e fixar nitrogênio atmosférico, além de servir como forrageira (LIMA et al., 2003). No entanto, A. pintoi apresenta pouca oferta de sementes, baixa produtividade em determinados locais e propagação, em geral, por mudas. Essa última característica aumenta o seu custo de implantação que é de R \$11.420,00 hectare/ano (Tabela 3) quando comparada aos demais tratamentos testados no presente estudo.

O controle das espécies exóticas invasoras em experimentos de restauração tem sido feito, geralmente, com herbicida (CAVA et al., 2016) por ser considerado uma ferramenta extremamente eficiente para inibir o crescimento dessas espécies (BOSSARD; RANDALL; HOSHOVSKY, 2000). Ao se simular o uso do herbicida seletivo para o controle de plantas daninhas de folhas estreitas, o custo total estimado (implantação + manutenção) foi de $\mathrm{R} \$ 1.115,00$ ha/ano, usando-se o herbicida Verdict ${ }^{\circledR}$, e, para o Glifosato ${ }^{\circledR}$, foi de $\mathrm{R} \$ 1.200,00$. Ambos menores que os custos das demais práticas testadas (Tabela 3).

Embora estes herbicidas tenham vantagens por apresentarem custos mais baixos e maior facilidade para uso em áreas grandes, cabe ressaltar que, ao se avaliar o custo/benefício, verifica-se que pode haver consequências para importantes processos nos ecossistemas e dificultar a restauração. Os herbicidas não seletivos podem afetar negativamente espécies nativas, prejudicando o banco de sementes do solo e a regeneração natural por sementes ou rebrotas (SILVEIRA et al., 2013; WAGNER; NELSON, 2014).

O uso de herbicida Glifosato ${ }^{\circledR}$ deve ser restrito às áreas com baixa cobertura de dossel $(<70 \%)$ e poucas nativas, pois esta técnica é a mais prejudicial à regeneração natural, com alta mortalidade de indivíduos de pequeno porte (73\%) quando a aplicação é feita em áreas com densa infestação de gramíneas 
(100\%), (TOREZAN; MANTOANI, 2013; MANTOANI; DIAS; TOREZAN, 2016).

O Glifosato ${ }^{\circledR}$ é um dos mais estudados no mundo, com uma das maiores bases de dados em termos de segurança ambiental e saúde humana (GIESY; DOBSON; SOLOMON, 2000; WILLIAMS; KROES; MUNRO, 2000). Na Mata Atlântica, em experimento de restauração, o controle de gramíneas exóticas com herbicida atuou positivamente no crescimento das mudas de espécies nativas (SILVEIRA et al., 2013; KLIPPEL et al., 2015) e na regeneração de espécies lenhosas e ruderais nativas. Ainda que não tenha sido encontrado resíduos de Glifosato ${ }^{\circledR}$ no solo e na água, foi registrado nos sedimentos, o que indica a necessidade de estabelecer medidas de conservação de solo e implantação de faixas de proteção para o uso desse herbicida na restauração de áreas ripárias (FLORIDO, 2015).

Outro aspecto que deve ser levado em consideração, é que, embora a braquiária seja uma espécie com alta capacidade de competir com as espécies nativas, ela, assim como qualquer cobertura vegetal, é importante para proteger o solo e conter processos erosivos. Ao retirar a braquiária de forma integral, sobretudo em áreas com declividade acentuada, o resultado pode ser a exposição excessiva do solo, provocando prejuízos na estrutura física e biológica do solo. A substituição paulatina da braquiária por espécies nativas deve ser indicada nesses locais. Segundo Santana et al. (2003) a braquiária não permite o movimento do solo, sendo uma das melhores alternativas para reduzir a erosão, assim como as leguminosas de cobertura.

$\mathrm{O}$ avanço nas técnicas de restauração, sobretudo no bioma Cerrado, depende do estabelecimento de práticas efetivas, menos onerosas e menos impactantes para controle de espécies exóticas invasoras. A presença dominante de espécies exóticas, em áreas de Cerrado, confere um filtro biológico importante que, muitas vezes, não consegue ser suplantado pelas espécies nativas. Espécies nativas com potencial para o controle de espécies exóticas invasoras podem auxiliar nas práticas de restauração.

\section{CONCLUSÕES}

Em áreas em processo de restauração ecológica de zonas ripárias, os dois métodos, manta plástica e semeadura em alta densidade do cultivar estilosantes Campo Grande, reduziram o capim braquiária, independentemente do período de implantação. Entre os dois métodos, os resultados apontam para o uso do cultivar estilosantes Campo Grande, pela facilidade de implantação em campo, menor custo (R $\$ 1.840,00)$ quando comparada à manta plástica $(\mathrm{R} \$ 2.368,00)$ e possível diminuição dos gastos com adubação de cobertura. É importante que acompanhamento de longo prazo seja conduzido visando verificar o comportamento das espécies vegetais no espaço e no tempo.

\section{AGRADECIMENTOS}

Ao CNPq e a Embrapa pelas bolsas concedidas e pelo financiamento do projeto AquaRipária (proc.561944/2010-5) e a Embrapa Cerrados pelo apoio logístico.

\section{REFERÊNCIAS}

ALCÂNTARA, A. F. et al. Adubação verde na recuperação da fertilidade de um latossolo vermelho - escuro degradado. Pesquisa Agropecuária Brasileira, Brasília, v. 35, n. 2, p. 277-288, 2000.

ANDRADE, C. M. S.; ASSIS, G. M. L.; SALES, M. F. L. Estilosantes Campo Grande: leguminosa forrageira recomendada para solos arenosos do Acre. Rio Branco: Embrapa Acre, 2010. 12 p. Comunicado técnico, 55).

ANDRADE, R. P.; KARIA, C. T. Uso de Stylosanthes em pastagens no Brasil. In: SIMPÓSIO DE FORRAGICULTURA E PASTAGENS, 2000, Lavras. Anais... Lavras: Universidade Federal de Lavras, 2000. BARCELLOS, A. O. et al. Potencial e uso de leguminosas forrageiras dos gêneros Stylosanthes, Arachis e Leucaena. In: SIMPÓSIO SOBRE MANEJO DE PASTAGEM, 17., 2000, Piracicaba. Anais... Piracicaba: FEALQ, 2001.

BARCELLOS, A. O. et al. Sustentabilidade da produção animal baseada em pastagens consorciadas e no emprego de leguminosas exclusivas, na forma de banco de proteína, nos trópicos brasileiros. 
Revista Brasileira de Zootecnia, Viçosa, MG, v. 37, p. 51-67, 2008.

BOSSARD, C. C.; RANDALL, J. M.; HOSHOVSKY, M. C. (Ed.). Invasive plants of California's wildlands. Berkeley: University of California Press, 2000. 360 p.

CAVA, M. G. B. et al. Comparação de técnicas para restauração da vegetação lenhosa de Cerrado em pastagens abandonadas. Hoehnea, São Paulo, v. 43, n. 2, p. 301-315, 2016.

COSTA, L. C.; SARTORI, A. L. B.; POTT, A. Estudo taxonômico de Stylosanthes (Leguminosae-Papilionoideae-Dalbergieae) em Mato Grosso do Sul, Brasil. Rodriguésia, Rio de Janeiro, v. 59, p. 547-572, 2008. EMBRAPA. Cultivo e uso do Estilosantes-campo-grande. Campo Grande: Embrapa Gado de Corte, 2007. 11 p. (Comunicado técnico, 105).

FIGUEIREDO, J. B. R. et al. Comparação de diferentes técnicas de combate a braquiária (Urochloa decumbens) em baixada alagável no Parque Nacional da Serra do Cipó, MG. In: CONGRESSO DE ECOLOGIA DO BRASIL, 9., 2009, São Lourenço. Anais... São Lourenço: Sociedade Brasileira de Ecologia, 2009. p. 1-3.

FLORIDO, F. G. Controle de plantas competidoras na restauração ecológica. 2015. 133 f. Dissertação (Mestrado) - Universidade de São Paulo, Escola Superior de Agricultura "Luiz de Queiroz", Piracicaba, 2015.

GIESY, J. P.; DOBSON, S.; SOLOMON, K. R. Ecotoxicological risk assessment for roundup herbicide. Reviews of Environmental Contamination and Toxicology, New York, v. 167, p. 35-120, 2000.

INSTITUTO NACIONAL DE METEOROLOGIA. Inmet. 2014. Disponível em: $<$ http://www.inmet.gov.br/climato/mapclima.html>. Acesso em: 13 jan. 2014.

KARIA, C. T.; ANDRADE, R. P. Avaliação preliminar de espécies forrageiras no Centro de Pesquisa Agropecuária dos Cerrados: perspectivas futuras. In: SIMPOSIO SOBRE O CERRADO, 8.; INTERNATIONAL SYMPOSIUM ON TROPICAL SAVANNAS, 1996, Brasília. Anais... Planaltina: EMBRAPA; CPAC, 1996. p. 471-475.

KARIA, C. T. et al. Caracterização morfológica de acessos do gênero Stylosanthes no banco ativo de germoplasma da Embrapa Cerrados - Coleção 1994/1995. Planaltina: Embrapa Cerrados, 2002. (Boletim de desenvolvimento e pesquisa, 72).

KLIPPEL, V. H. et al. Avaliação de métodos de restauração florestal de Mata de Tabuleiros-ES. Revista Árvore, Viçosa, MG, v. 39, n. 1, p. 69-79, 2015.

KRAPOVICKAS, A.; GREGORY, W. C. Taxonomia del género Arachis Leguminosae. Bonplandia, Corrientes, v. 8, p. 1-186, 1994.

LEWIS, G. L.; MACKINDER, B.; LOCK, M. Legumes of the world. [s. 1.]: Royal Botanic Gardens, $2005.578 \mathrm{p}$.

LIMA, J. A. et al. Amendoim forrageiro (Arachis pintoi Krapov \& Gregory). Lavras: Editora UFLA, 2003. (Boletim de extensão).

MANTOANI, M. C.; DIAS, J.; TOREZAN, J. M. D. Roçagem e aplicação de herbicida para controle de Megathyrsus maximus: danos sobre a vegetação preexistente em um reflorestamento de 20 anos. Ciência Florestal, Santa Maria, v. 26, n. 3, p. 839-851, 2016.

MARTINS, A. F. Controle de Urochloa decumbens Stapf em área de restauração ecológica com plantio total, Floresta Estacional Semidecidual, Itu-SP. 2011. 112 f. Dissertação (Mestrado) - Universidade de São Paulo, Escola Superior de Agricultura "Luiz de Queiroz", Piracicaba, 2011.

MARTINS, C. R.; LEITE, L. L.; HARIDASAN, M. Capim-gordura (Melinis minutiflora P. Beauv.), uma gramínea exótica que compromete a recuperação de áreas degradadas em unidades de conservação. Revista Árvore, Viçosa, MG, v. 28, n. 5, p. 739-747, 2004.

MIYASAKA, S. et al. Histórico de estudos de adubação verde, leguminosas viáveis e suas caraterísticas. In: FUNDAÇÃO CARGILL. A adubação verde no Brasil. Campinas: Fundação Cargill, 1984. p. 64-123. MONTENEGRO, R.; PINZÓN, B. Maní forrajero (Arachis pintoi Krapovickas e Gregory): una alternativa para el sostenimiento de la ganaderia en Panamá. Panamá: IDIAP, 1997. 20 p.

NAVE, A. G. et al. Descrição das ações operacionais de restauração. In: RODRIGUES, R. R.; BRANCALION, P. H. S.; ISERNHAGEN I. (Org.). Pacto pela restauração da Mata Atlântica: referencial dos conceitos e ações de restauração florestal. São Paulo: Instituto Bio Atlântica, 2009. v. 1.

PEREIRA, J. R.; CAMPOS, A. T. Controle da braquiária como invasora. Juiz de Fora: Embrapa Gado 
de Leite, 2001. (Instrução técnica para o produtor de leite, 26).

PHENGSAVANH, P.; LEDIN, I. Effect of stylo 184 (Stylosanthes guianensis CIAT 184) and gamba grass (Andropogon gayanus cv. Kent) in diets for growing goats. Livestock Research for Rural Development, Cali, v. 15, n. 10, 2003. Disponível em: <http://www.lrrd.org/lrrd15/10/cont1510.htm>. Acesso em: 13 dez. 2011.

PIVELLO, V. R. Invasões biológicas no cerrado brasileiro: efeitos da introdução de espécies exóticas sobre a biodiversidade. Ecologia Info, Sweden, n. 33, 2011.

REATTO, A. Caracterização de solos em três áreas de matas ripárias em processo de restauração ecológica no Distrito Federal. Planaltina: Embrapa Cerrados, 2013. 13 p. (Relatório da Embrapa Cerrados). RINCÓN, C. A. et al. Maní forrajero perenne (Arachis pintoi Krapovickas e Gregory): uma alternativa para ganaderos e agricultores. Bogotá: Instituto Colombiano Agropecuário, 1992. 23 p. (Boletín Técnico, 219).

RODRIGUES, E. R. Controle biológico de Brachiaria decumbens Stapf em área de reserva legal em processo de recuperação, na região do Pontal do Paranapanema, São Paulo, Brasil. $2010.77 \mathrm{f}$. Tese (Doutorado) - Universidade Estadual Paulista, Instituto de Biociências de Rio Claro, Rio Claro, 2010. RODRIGUES, J. E. L. F. et al. A importância do feijão de porco (Canavalia Ensiformis DC.) como cultura intercalar em rotação com milho e feijão cauoi em cultivo de coqueirais no Município de Ponta de Pedras/Marajó - PA. Belém: Embrapa Amazônia Oriental, 2004. 4 p. (Comunicado Técnico, 96).

SAMPAIO, A. B.; HOLL, K. D.; SCARIOT, A. Regeneration of seasonal deciduous forest tree species in long-used pastures in Central Brazil. Biotropica, Washington, v. 39, n. 5, p. 655-659, 2007.

SAMPAIO, R. A.; ARAÚJO, W. F. Importância da cobertura plástica do solo sobre o cultivo de hortaliças. Agropecuária Técnica, Areia, v. 22, n. 1/2, p. 1-12, 2001.

SANTANA, R. R. et al. Potential of trees, grasses, and turf legumes for restoring eroded soils. Communications in Soil Science and Plant Analysis, New York, v. 34, n. 15-16, p. 2149-2162, 2003.

SILVEIRA, E. R. et al. Controle de gramíneas exóticas em plantio de restauração do Cerrado. In: DURIGAN, G.; RAMOS, V. S. (Org.). Manejo adaptativo: primeiras experiências na restauração de ecossistemas. São Paulo: Páginas \& Letras, 2013. v. 1. p. 5-7.

TOREZAN, J. M. D.; MANTOANI, M. C. Controle de gramíneas no subosque de florestas em restauração. In: DURIGAN, G.; RAMOS, V. S. (Org.). Manejo adaptativo: primeiras experiências na restauração de ecossistemas. São Paulo: Páginas \& Letras, 2013. v. 1. p. 1-4.

TUFFI SANTOS, L. D. et al. Exsudação radicular do glifosato por Brachiaria decumbens e seus efeitos em plantas de eucalipto e na respiração microbiana do solo. Planta Daninha, Viçosa, MG, v. 23, n. 1, p. 143-152, 2005.

VALLS, J. F. M.; MAASS, B. L.; LOPES, C. R. Genetic resources of wild Arachis and genetic diversity. In: KERRIDGE, P. C.; HARDY, B. (Ed.). Biology and agronomy of forage Arachis. Cali: CIAT, 1994. p. 28-42.

WAGNER, V.; NELSON, C. R. Herbicides can negatively affect seed performance in native plants. Restoration Ecology, Washington, n. 22, p. 288-291, 2014.

WILLIAMS, G. M.; KROES, R.; MUNRO, I. C. Safety evaluation and risk assessment of the herbicide roundup and its active ingredient, glyphosate, for humans. Regulatory Toxicology and Pharmacology, Orlando, v. 31, p. 117-165, 2000. 